$\begin{array}{lll}\text { Kosuke Ishizuka, MD } & \text { Kiyoshi Shikino, MD, PhD } & \text { Masatomi Ikusaka, MD, PhD } \\ \begin{array}{l}\text { Department of General Medicine, } \\ \text { Chiba University Hospital, }\end{array} & \begin{array}{l}\text { Department of General Medicine, } \\ \text { Chiba University Hospital, }\end{array} & \begin{array}{l}\text { Department of General Medicine, } \\ \text { Chiba University Hospital, }\end{array} \\ \text { Chiba, Japan } & \text { Chiba, Japan }\end{array}$

\title{
Anterior interosseous nerve palsy caused by Parsonage-Turner syndrome
}

\begin{abstract}
58-YeAR-OLD MAn presented with difficulA ty in moving his left hand. Three weeks before this presentation, he had symptoms of an upper respiratory tract infection, which resolved spontaneously in several days. And 1 week after that, he experienced a severe stabbing pain in his entire left upper arm, which resolved in several days. At that time, he also developed difficulty in moving the thumb and index finger of his left hand.

On physical examination, manual muscle testing showed weakness in the left opponens pollicis muscle and flexor digitorum profundus muscle of the left index finger, without apparent atrophy. There was no evidence of sensory disturbance. Tendon reflexes were normal in the upper and lower extremities, and pathological reflexes were negative.

The OK sign test was positive in the left hand (Figure 1). Blood tests, cervical magnetic resonance imaging, electromyography, and nerve conduction velocity testing showed no abnormal findings. Based on the history, symptoms, OK sign test, and lack of abnormalities on other parts of the workup, the patient was diagnosed with Parsonage-Turner syndrome.

His symptoms resolved in several months after rehabilitation with physical therapy.
\end{abstract}

\section{PARSONAGE-TURNER SYNDROME: DISTINGUISHING FEATURES}

Parsonage-Turner syndrome, also referred to as idiopathic brachial plexopathy or neuralgic amyotrophy, is characterized by an acute onset of unilateral neuralgia of the upper extremdoi:10.3949/ccjm.88a.20019

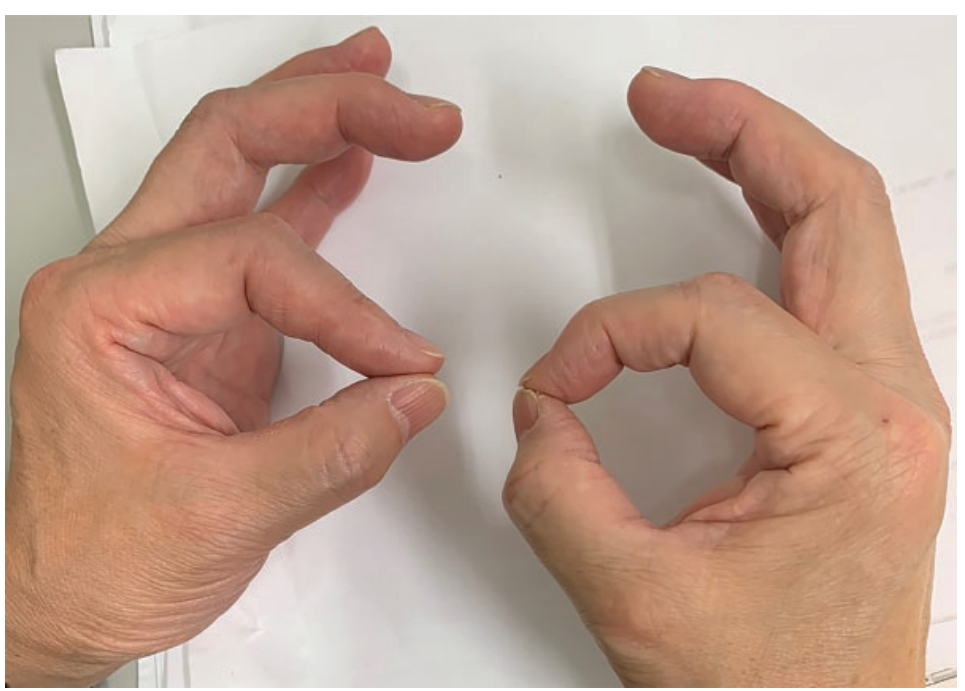

Figure 1. The OK sign test was positive in the left hand, with reduced flexion in the first interphalangeal joint and the second distal interphalangeal joint, as compared with the corresponding joints of the nonaffected (right) hand.

ity. ${ }^{1}$ The neuralgia resolves in several days to 2 weeks. ${ }^{1}$ Thereafter, muscle atrophy and motor paralysis develop in the ipsilateral side. ${ }^{1}$ The most commonly affected muscles are proximal ones, including the supraspinatus, infraspinatus, anterior serratus, deltoid, and biceps brachii. ${ }^{2}$ Cases of selective anterior-posterior interosseous nerve palsy have also been reported. ${ }^{3}$

The anterior interosseus nerve is a branch of the median nerve, which supplies motor innervation to the anterior forearm flexors, the thenar muscles, and the lateral 2 lumbricals. It also supplies sensory innervation to the lateral palm and anterior lateral 3 and one-half fin- 
gers. Both proximal median nerve palsy above the elbow and carpal tunnel syndrome result in reduced sensation in the thumb, index finger, and middle finger. Anterior interosseus nerve palsy alone does not cause sensory disturbance.

Akane et $\mathrm{al}^{4}$ reported that 27 of $51(52.9 \%)$ patients with anterior-posterior interosseous nerve palsy had preceding upper extremity pain, and 9 of the 27 (33.3\%) had pain in the entire arm. In the cases that began with pain, the first signs of weakness appeared within 7 days in $66.6 \%$. A preceding infection was observed in 3 cases.

The $\mathrm{OK}$ sign test is administered by asking patients to make an $\mathrm{OK}$ sign with the thumb and index finger. It is positive if it detects reduced flexion in the first interphalangeal joint and the second distal interphalangeal joint, as compared with the corresponding joints of the

\section{REFERENCES}

1. Parsonage MJ, Turner JW. Neuralgic amyotrophy; the shoulder-girdle syndrome. Lancet 1948; 1(6513):973-978. doi:10.1016/s0140-6736(48)90611-4

2. Fukushima K, Ikeda S. Neuralgic amyotrophy. Brain Nerve 2014; 66(12):1421-1248. Japanese. doi:10.11477/mf.1416200056

3. van Alfen N, van Engelen BG. The clinical spectrum of neuralgic amyotrophy in 246 cases. Brain 2006; 129(Pt 2):438-450. doi:10.1093/brain/awh722

4. Akane M, Iwatsuki K, Tatebe M, et al. Anterior interosseous nerve and posterior interosseous nerve involvement nonaffected hand, and thus is useful in the diagnosis of anterior interosseous nerve palsy. ${ }^{5}$

Electromyography usually indicates acute denervation and axonal degeneration with potential positive fibrillation spike waves. ${ }^{6}$ However, $3.7 \%$ of patients with Parsonage-Turner syndrome show no abnormalities on electromyography ${ }^{2}$ because the alterations are generally not perceptible until 3 weeks after the onset of symptoms. ${ }^{6}$ Some cases also reported no abnormalities on magnetic resonance imaging or nerve conduction velocity testing. ${ }^{4}$ As patients with interosseous nerve palsy often lack characteristic imaging findings, careful historytaking is important in the diagnosis.

\section{DISCLOSURES}

The authors report no relevant financial relationships which, in the context of their contributions, could be perceived as a potential conflict of interest.

in neuralgic amyotrophy. Clin Neurol Neurosurg 2016; 151:108-112. doi:10.1016/j.clineuro.2016.11.001

5. Rodner CM, Tinsley BA, O'Malley MP. Pronator syndrome and anterior interosseous nerve syndrome. J Am Acad Orthop Surg 2013; 21(5):268-275. doi:10.5435/JAAOS-21-05-268

6. Monteiro Dos Santos RB, Dos Santos SM, Carneiro Leal FJ, Lins OG, Magalhães C, Mertens Fittipaldi RB. Parsonage-Turner syndrome. Rev Bras Ortop 2015; 50(3):336-341. doi:10.1016/j.rboe.2015.04.002

Address: Kosuke Ishizuka, MD, Department of General Medicine, Chiba University Hospital, 1-8-1, Inohana, Chuo-ku, Chiba-City, Chiba Pref. Japan; e103007c@yokohama-cu.ac.jp 